ARTICLE

\title{
Photocatalyzed cycloaromatization of vinylsilanes with arylsulfonylazides
}

\author{
Fengjuan Chen ${ }^{1,4}$, Youxiang Shao ${ }^{2,4}$, Mengke Li $i^{3,4}$, Can Yang$^{1}$, Shi-Jian Su (i) ${ }^{3 凶}$, Huanfeng Jiang ${ }^{1}$, \\ Zhuofeng Ke(i) ${ }^{2 凶} \&$ Wei Zeng (i) ${ }^{1 凶}$
}

Sila-molecules have recently attracted attention due to their promising applications in medical and industrial fields. Compared with all-carbon parent compounds, the different covalent radius and electronegativity of silicon from carbon generally endow the corresponding sila-analogs with unique biological activity and physicochemical properties. Vinylsilanes feature both silyl-hyperconjugation effect and versatile reactivities, developing vinylsilane-based Smiles rearrangement will therefore provide an efficient platform to assemble complex silacycles. Here we report a practical Ir(III)-catalyzed cycloaromatization of ortho-alkynylaryl vinylsilanes with arylsulfonyl azides for delivering naphthyl-fused benzosiloles under visible-light photoredox conditions. The combination of experiments and density functional theory (DFT) energy profiles reveals the reaction mechanism involving $\alpha$ silyl radical Smiles rearrangement.

\footnotetext{
${ }^{1}$ Key Laboratory of Functional Molecular Engineering of Guangdong Province, School of Chemistry and Chemical Engineering, South China University of Technology, Guangzhou, China. ${ }^{2}$ School of Materials Science and Engineering, PCFM Lab, Sun Yat-sen University, Guangzhou, China. ${ }^{3}$ State Key Laboratory of Luminescent Materials and Devices, Institute of Polymer Optoelectronic Materials and Devices, South China University of Technology, Guangzhou, China. ${ }^{4}$ These authors contributed equally: Fengjuan Chen, Youxiang Shao, Mengke Li. ®email: mssjsu@scut.edu.cn; kezhf3@mail.sysu.edu.cn; zengwei@scut.edu.cn
} 
S ilahydrocarbons are sometimes encountered in pharmaceuticals and material chemistry ${ }^{1-4}$. Compared with allcarbon parent compounds, Si-element generally endows the corresponding hydrocarbons with unique biological activity and physical-chemical properties ${ }^{5-8}$, which are mainly determined by the different covalent radius and electronegativity of silicon from carbon. In these regards, arene-fused siloles have especially attracted many concerns due to their promising applications in electronic and optoelectronic devices ${ }^{9-13}$. In 2012, $\mathrm{Xi}^{14}$ and Chatani ${ }^{15}$ pioneeringly explored intermolecular coupling-cyclization of alkynes with 2-silylaryl bromides and 2silylphenylboronic acids to produce 2,3-difunctionalized benzosiloles through Si-C bond cleavage (Fig. 1a). Subsequently, $\mathrm{He}^{16}$ developed rhodium-catalyzed intramolecular silicoamination of ortho-alkynylarylsilanes to construct indole-fused benzosiloles (Fig. 1b). In light of that modifying the $\pi$ conjugated system of parent siloles could possibly improve their corresponding photophysical properties. Thus, there has been an ever-increasing demand for the rapid assembly of diversified polycycle-fused siloles ${ }^{17-22}$.

Aryl migration via Smiles rearrangement is a powerful tool for the synthesis of polycyclic arenes ${ }^{23-25}$. However, the modes of radical Smiles rearrangement are very limited. Up to now, only acarbonyl radical ${ }^{26-30}, \beta$-aminoalkyl radical ${ }^{31-33}, N$-centered radical $^{34}$, and ketyl radical ${ }^{35}$ - triggered Smiles rearrangement have been exploited to construct nitrogen-heterocycles, and vinylsilane-based Smiles rearrangement keep unexplored. As is well known, vinylsilanes have proven to be important "alkene" sources in Hiyama coupling, which could efficiently incorporate $\mathrm{C}=\mathrm{C}$ bond in a particular molecule with the release of silyl moiety ${ }^{36}$; Meanwhile, the high electronegativity of carbon (2.35) relative to silicon $(1.64)^{37}$ and silyl-hyperconjugation effect (the so-called $\beta$-effect $)^{38-40}$ generally endow these compounds with the versatile reactivity. For example, Jun ${ }^{41}$ reported that $\mathrm{Rh}(\mathrm{I})$ catalyzed cross-coupling of aldehydes with vinylsilanes led to the formation of $\beta$-acylsilanes via $\beta$-silylethylrhodium(III) intermediates. On the contrary, Buchwald ${ }^{42}$ and Miura ${ }^{43}$ demonstrated that $\mathrm{Cu}(\mathrm{I})$-catalyzed addition-coupling of vinylsilanes with amines could produce $a$-aminosilanes. Thus it can be seen that developing vinylsilane-based coupling-cyclization will possibly establish an efficient platform to assemble complex silacycles. Again, azides could be employed as potential nitrogen radical precursors to enable $\mathrm{C}-\mathrm{H}$ amination ${ }^{44}$ under photocatalysis systems. Accordingly, visible-light catalyzed coupling of vinylsilanes with arylsulfonylazides could possibly generate $\alpha$-silyl radicals and initiate the silylalkene Smiles rearrangement.

Here, we show a cycloaromatization of ortho-alkynylarylsilylalkenes with arylsulfonyl azides for rapid assembly of 2,3naphthyl-fused benzosiloles via a cascade S-N/C-S bond cleavage in the presence of visible light (Fig. 1c).

\section{Results}

Investigation of reaction conditions. The choice of ortho-alkynylaryl vinylsilane 1a was motivated by the notion that alkynyl and vinyl groups could possibly trap radicals to assemble complex silacycles under blue light-emitting diodes (LEDs) irradiation. After an extensive screening of various reaction parameters, we were pleased to find that the treatment of substrate 1a with $\mathrm{TsN}_{3} \mathbf{2 a}$ under photocatalyzed system did afford a large $\pi$-conjugated benzosilafluorene 3a with an unexpected loss of sulfonylazide $\left(\mathrm{SO}_{2} \mathrm{~N}_{3}\right)$ group from $\mathrm{TsN}_{3}$ (Fig. 2). Optimization of the reaction conditions afforded the yield of 3 a reaching $69 \%$ in the presence of $0.5 \mathrm{~mol} \%$ of $\left[\operatorname{Ir}\left\{\mathrm{dt}(\mathrm{tBu})_{2} \mathrm{ppy}_{2}(\mathrm{dtbbpy})\right]\left[\mathrm{PF}_{6}\right] \quad(\mathbf{P C 1})\right.$ and 1,4-diazabicyclo (2.2.2) octane (DABCO) (1.5 equiv) in 1,4-dioxane at $80^{\circ} \mathrm{C}$ for $24 \mathrm{~h}$ under air atmosphere (Fig. 2 Table, entry 1). On the contrary, other catalysts such as $\mathrm{fac}$-Ir(ppy) ${ }_{3}$ (PC2), Eosin Y, MesAcr ${ }^{+} \mathrm{ClO}_{4}{ }^{-}$ (PC3), 2,4,6-triphenylpyrylium tetrafluoroborate (TPP), and $\mathrm{Ru}$ (bpy) ${ }_{3} \mathrm{Cl}_{2}$ (PC4) did not give the product $3 \mathbf{a}$ in more than $5 \%$ yield (entries 2-6 vs 1). Meanwhile, utilization of different solvent systems (entries 7-9) or inorganic bases such as $\mathrm{K}_{2} \mathrm{CO}_{3}$ and $\mathrm{Cs}_{2} \mathrm{CO}_{3}$ (entries 10-11) made this transformation very sluggish. Similarly, running the reaction under room temperature, Ar atmosphere, and green-light irradiation also led to significantly lower yields, respectively (entries $12-14$ vs 1 ). Notably, control experiments under these optimized conditions indicated that 2,3-naphthyl-fused benzosilole 3a could not be observed at all in the absence of light or photocatalysts (PC) (entries 15-16).
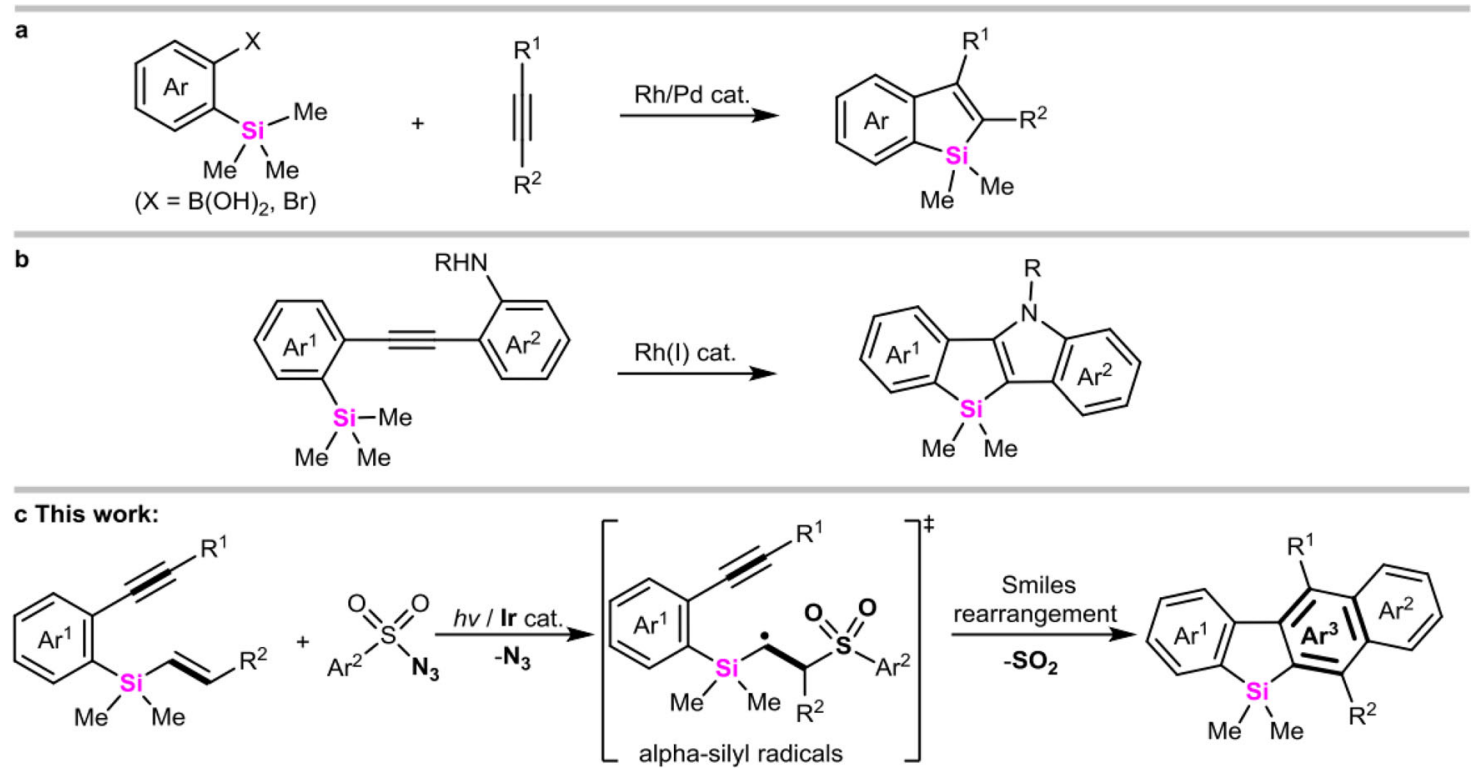

Fig. 1 Strategies to access benzosiloles. a Rh/Pd-catalyzed intermolecular cyclovinylation of arylalkylsilanes with alkynes. b Rh(I)-catalyzed intramolecular aminosilylation of ortho-alkynylarylsilanes. c Photocatalyzed carbocyclization of vinylsilanes with arylsulfonyl azides via alpha-silyl radical Smiles rearrangement. 

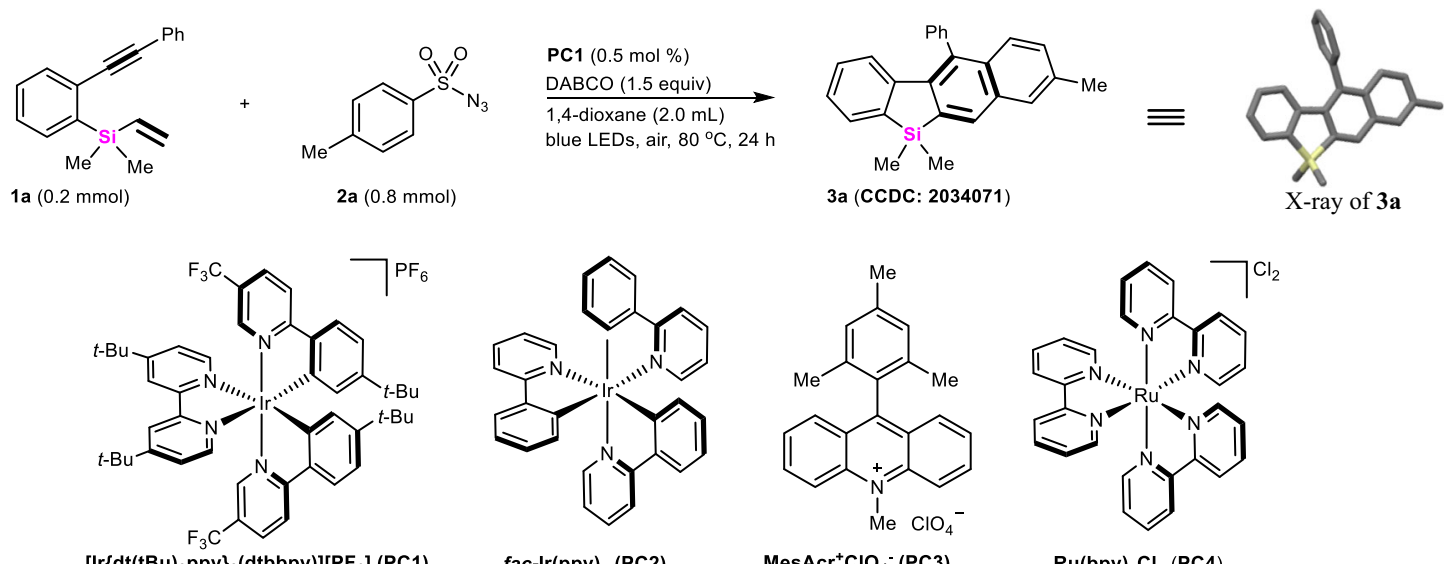<smiles>Cc1cc([N+](=O)[O-])c(-c2c3ccccc3[n+]([N+](=O)[O-])c3ccccc23)c([N+](=O)[O-])c1</smiles>

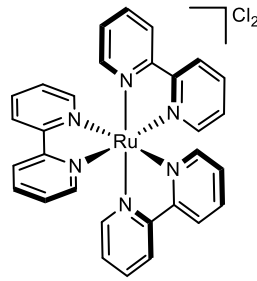

$\left[\operatorname{Ir}\left\{\mathrm{dt}(\mathrm{tBu})_{2} \mathrm{ppy}\right\}_{2}(\mathrm{dtbbpy})\right]\left[\mathrm{PF}_{6}\right](\mathrm{PC} 1)$

fac-Ir(ppy $)_{3}(\mathrm{PC} 2)$

$\mathrm{MesAcr}^{+} \mathrm{ClO}_{4}^{-}(\mathrm{PC} 3)$

$\mathrm{Ru}(\mathrm{bpy})_{3} \mathrm{Cl}_{2}(\mathrm{PC} 4)$

\begin{tabular}{|c|c|c|}
\hline Entry & Changes to standard conditions & Yield 3a (\%) \\
\hline 1 & none & 69 \\
\hline 2 & $f a c-\operatorname{Ir}(\mathrm{ppy})_{3}(\mathbf{P C 2})$ & 0 \\
\hline 3 & Eosin Y & $<5$ \\
\hline 4 & $\mathrm{MesAcr}^{+} \mathrm{ClO}_{4}^{-}(\mathbf{P C} 3)$ & $<5$ \\
\hline 5 & ТPP & 0 \\
\hline 6 & $\mathrm{Ru}(\mathrm{bpy})_{3} \mathrm{Cl}_{2}(\mathbf{P C} 4)$ & 0 \\
\hline 7 & $\mathrm{PhCF}_{3}$ & 44 \\
\hline 8 & DMF & 0 \\
\hline 9 & $\mathrm{CH}_{3} \mathrm{CN}$ & trace \\
\hline 10 & $\mathrm{~K}_{2} \mathrm{CO}_{3}$ & 10 \\
\hline 11 & $\mathrm{Cs}_{2} \mathrm{CO}_{3}$ & 15 \\
\hline 12 & room temperature & 38 \\
\hline 13 & Ar atmosphere & 34 \\
\hline 14 & green LEDs & 20 \\
\hline 15 & no light & 0 \\
\hline 16 & no PC & 0 \\
\hline
\end{tabular}

Fig. 2 Reaction development. All the reactions are conducted in sealed tubes, followed by flash chromatography on $\mathrm{SiO}_{2}$. The isolated yields are reported.

Substrate scope. With this optimized protocol, we examined the transformation of various ortho-alkynylaryl vinylsilanes (1) with para-methylphenylsulfonyl azide 2a. As summarized in Fig. 3, different sila-enynes 1 bearing electron-rich $(-\mathrm{Me},-\mathrm{Et},-n$-Bu, and $-\mathrm{MeO})$, halogen $(-\mathrm{F},-\mathrm{Cl}$ and $-\mathrm{Br})$, strong electron-withdrawing $\left(-\mathrm{CF}_{3}\right)$, and even vinylsilyl substituent at the para-position of alkynylphenyl groups $\left(\mathrm{R}^{1}=\right.$ phenyl), successfully underwent carbocyclization-aromatization with $\mathrm{TsN}_{3} \quad$ (2a) to afford 4(4-substituted-phenyl)-2,3-benzosilafluorenes $\mathbf{3 a}, \mathbf{3 b}, \mathbf{3} \mathbf{d}-\mathbf{3 k}$ in moderate to good yields (50-71\%). Likewise, meta-methylphenylsubstituted alkynylaryl vinylsilane could react efficiently to provide $3 \mathrm{c}$ in $63 \%$ yield. Meanwhile, ortho-(1-heptynyl)-phenyl vinylsilane was also tolerable in this reaction to assemble 4 pentyl-substituted-2,3-benzosilafluorenes 31 (50\%). However, when the terminal alkyne-tethered arylvinylsilane was subjected to the reaction system, only a $15 \%$ yield of $\mathbf{3 m}$ was obtained. The evaluation of the substituent effect $\left(\mathrm{R}^{3}\right)$ from vinylsilyl benzene ring of $\mathbf{1}$ indicated that all of the electron-rich or electrondeficient silylarenes could smoothly react with $\mathrm{TsN}_{3}$ (2a) to furnish the desired products $\mathbf{3 n} \mathbf{- 3 q}$ with good conversions (58-68\% yields), regardless of electronic properties of substituents. It should be noted that hept-1-en-1-yldimethylsilane was not well tolerated under these conditions, only affording 1pentyl-2,3-benzosilafluorene $3 \mathbf{r}$ in $12 \%$ yield.

Interestingly, if vinyldimethylsilane $\mathbf{1}$ was switched to allyldimethylsilane 4 , an unexpected $[2+2+3]$ coupling-cyclization of ortho-alkynyaryl allyldimethylsilane $\mathbf{4}$ with arylsulfonyl azides $\mathbf{2}$ occurred (Fig. 4), affording a novel 6/7/7/6-fused silatetracyclic skeleton in good yields $\left(59-65 \%\right.$ for $\mathbf{5 a}-\mathbf{5 c}$ ) in which $\mathrm{SO}_{2}$ was kept untouched.

Next, we explored the substrate scope of sulfonyl azides by carrying out the cycloaromatization reaction with vinylsilane 1a (Fig. 5). Compared with electron-neutral phenylsulfonyl azides (60\% for 6a), 4-MeO, 4-Ph, 4-halo (F, Cl, Br, I), and 4-acetamidophenylsulfonyl azides could smoothly react with vinylsilane $\mathbf{1 a}$ to produce 2,3-benzosilafluorenes in $21-70 \%$ yields $(\mathbf{6 d}, \mathbf{6 e}, \mathbf{6 h}$, 6i, 6l, 6m, 6n). Of noted, 3-methylphenylsulfonyl azide, 3chlorophenylsulfonyl azide, and even 2-naphthylsulfonyl azide furnished $61-74 \%$ overall yields of isomers $6 \mathbf{b} / \mathbf{6 c}, \mathbf{6 f} / \mathbf{6 g}$, and $\mathbf{6 j} / \mathbf{6 k}$. Gratifyingly, the protocol was still shown to tolerate strong electron-withdrawing $\left(4-\mathrm{CF}_{3}, 4-\mathrm{CN}, 4\right.$-acyl, 4- $\left.\mathrm{CO}_{2} \mathrm{Et}, 4-\mathrm{CO}_{2} \mathrm{H}\right)$ substituted phenylsulfonyl azides and even 3-pyridylsulfonyl azide, giving $42-72 \%$ yields of $\mathbf{6 o - 6 t}$, respectively.

Application. To evaluate the potentiality of 2,3-naphthyl-fused benzosiloles in developing organic optoelectronic materials, 8bromo-5,5-dimethyl-11-phenyl-5H-benzo[b]naphtho[2,3-d] silole 61 was employed to react with anthracene-9,10-diyldiboronic acid 7 in the presence of Pd-catalysts, and highly $\pi$-conjugated teranthracene-tethered 1-phenyl-2,3-benzosilafluorene $\mathbf{8}$ which contains three anthracenyl units, could be obtained in $14 \%$ yield 

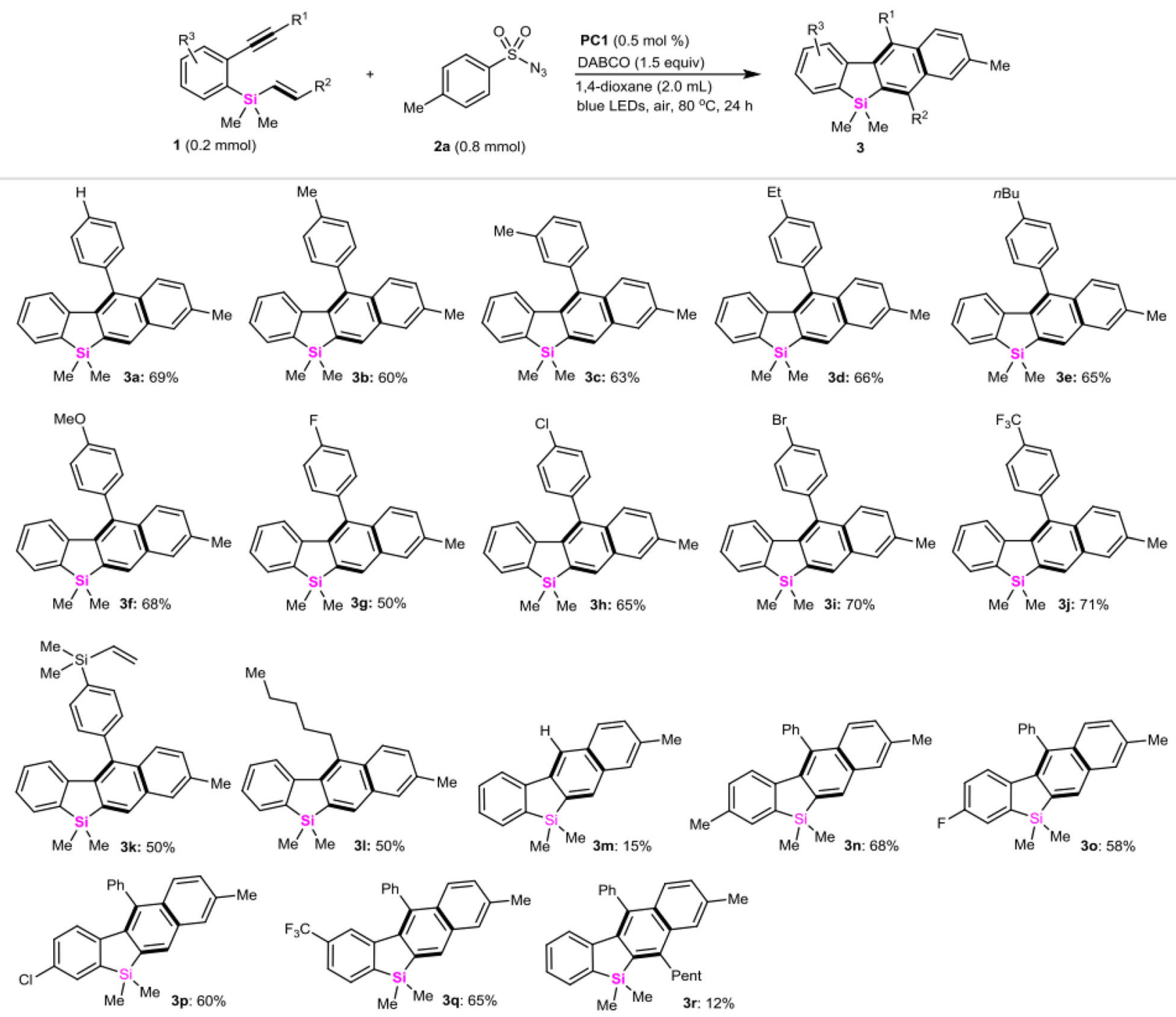

Fig. 3 Sila-enyne scope. All the reactions are conducted in sealed tubes, followed by flash chromatography on $\mathrm{SiO}_{2}$. The isolated yields are reported.
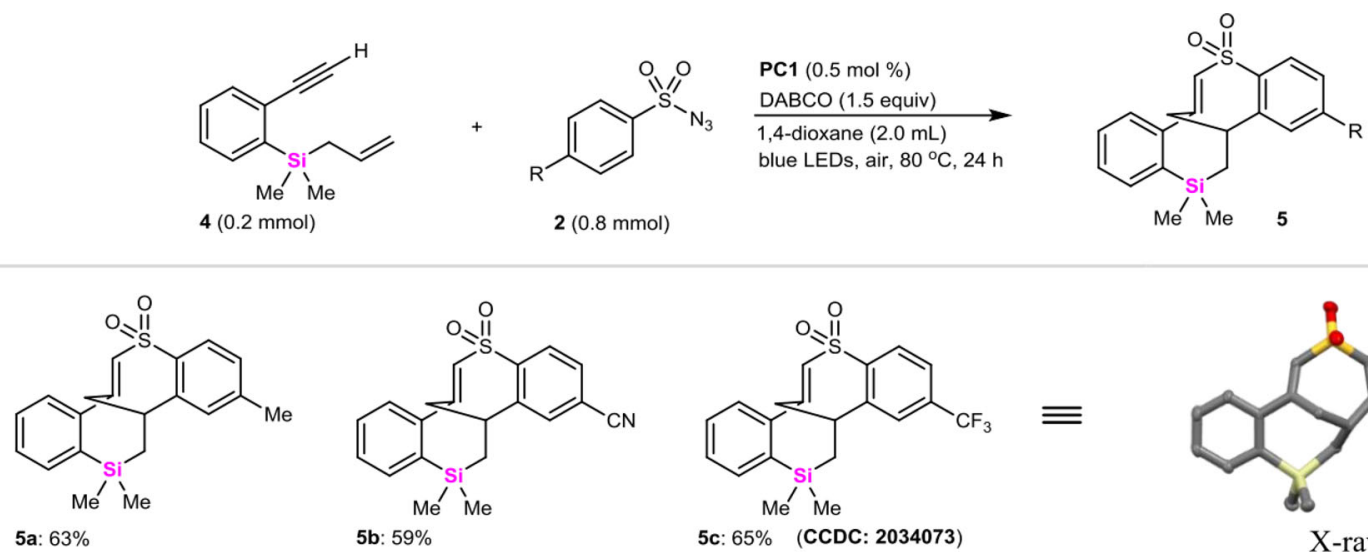

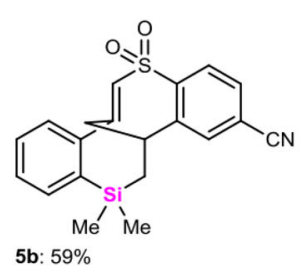

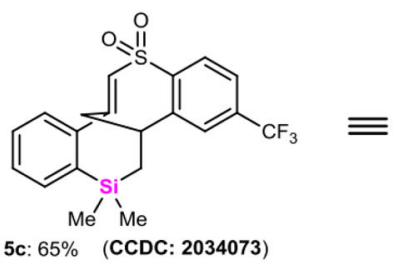

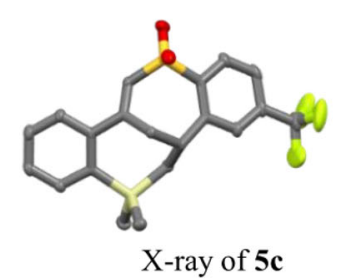

Fig. 4 The coupling-cyclization of allylic dimethylsilanes with arylsulfonyl azides. All the reactions are conducted in sealed tubes, followed by flash chromatography on $\mathrm{SiO}_{2}$. The isolated yields are reported. 

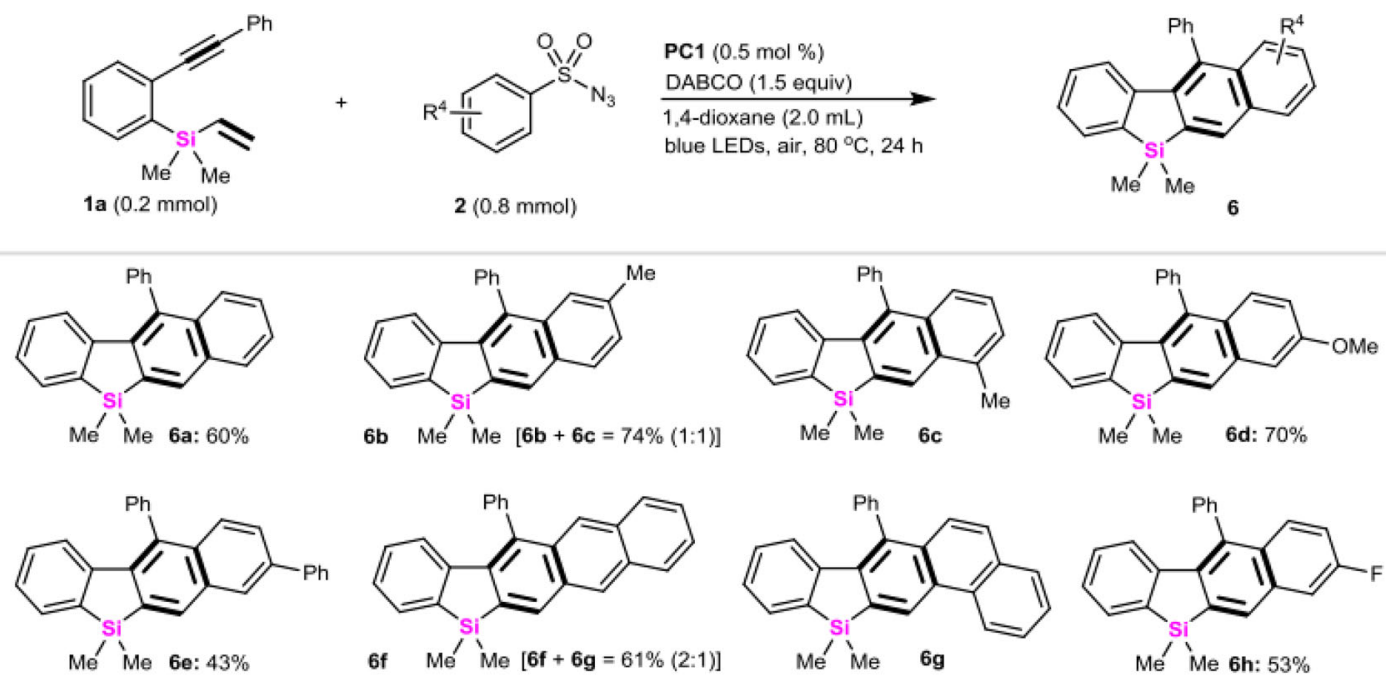<smiles>C[Si]1(C)c2ccccc2-c2c1cc1cc(Cl)ccc1c2-c1ccccc1</smiles>
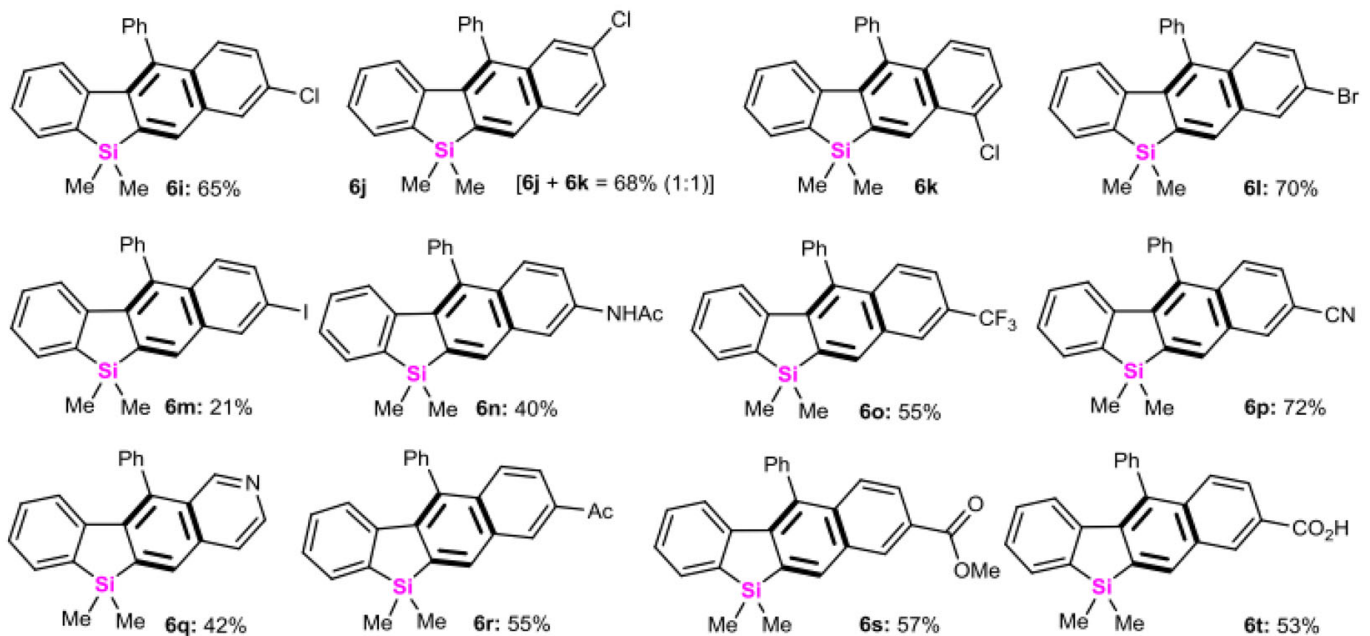

Fig. 5 Arylsulfonylazide scope. All the reactions are conducted in sealed tubes, followed by flash chromatography on $\mathrm{SiO}_{2}$. The isolated yields are reported and ratios of isomers are shown in parenthesis.

(Fig. 6a) (it should be noted that this transformation easily led to the protonation of anthracene-9,10-diyldiboronic acid 7 , affording 53\% yield of anthracence 9 (see Supplementary Information, pg S26)). Photophysical properties of benzosilole derivative 8 were investigated by ultraviolet-visible (UV-vis) absorption and photoluminescence (PL) spectra in diluted toluene solution $\left(10^{-5} \mathrm{M}\right)$ (Fig. $\left.6 \mathrm{~b}\right)$. The absorption bands in the long-wavelength region $(350-400 \mathrm{~nm})$ can be attributed to the $\pi-\pi^{*}$ transition of the anthracenyl units ${ }^{45}$. Both PL spectra at r.t. and $77 \mathrm{~K}$ exhibited a $0-0$ peak at $415 \mathrm{~nm}$, a $0-1$ sub-peak at $433 \mathrm{~nm}$, and a $0-2$ shoulder at $465 \mathrm{~nm}$. Meanwhile, a PL quantum yield of $51 \%$ was achieved, indicating that this molecular skeleton could be a promising building block for deep-blue luminescent materials.

Mechanistic investigations. Sulfonyl azides have been rarely converted into sulfonyl radicals in chemical transformation. Up to now, only Konig reported an example that sulfonyl azides were employed as precursors of nitrenes in visible-light photocatalysis ${ }^{46}$. More recently, Lam found that arylsulfonyl azides could be converted into arylsulfonyl radicals under the photocatalytic system, in which hydrogen abstraction from THF was involved ${ }^{47}$. However, our solvent screening indicated that this cycloaromatization could also be allowed in $\mathrm{PhCF}_{3}$ (Fig. 2, entry 7), in which hydrogen abstraction from $\mathrm{PhCF}_{3}$ is very difficult. The observation implied that sulfonyl azides could possibly produce sulfonyl radical via unstable arylsulfonyldiimide intermediates $\left(\mathrm{ArSO}_{2} \mathrm{~N}=\mathrm{NSO}_{2} \mathrm{Ar}\right)^{48}$, which is derived from the nitrene radical dimerization and protonation (this transformation was performed under air conditions, in which the synergistic cooperation of $\mathrm{O}_{2}$, and alkylamines (DABCO), etc. could possibly provide proton sources $)^{49}$. Given that disulfonylhydrazines could produce disulfonyldiimines via single electron transfer (SET) followed by denitrogenation to afford sulfonyl radicals ${ }^{50,51}$, we utilized sulfonylhydrazine $\mathbf{1 0}$ to react with 1a (Fig. 7a), the desired product $3 \mathbf{a}$ (30\%) could be obtained, this control experiment implied that disulfonyldiimines were possibly involved in this cycloaromatization.

In addition, when 2,2,6,6-tetramethyl-1-piperidinyloxy (TEMPO) (2.0 equiv) was applied to the reaction of vinylsilane 1a and $\mathrm{TsN}_{3}$, it was found that TEMPO completely inhibited the cycloaromatization of 1a, and sulfonyl ester 11 (HR-MS: 334.1448, Supplementary Fig. 3) (see Supplementary Information for the HR-MS) could be detected (Fig. 7b), confirming that sulfonyl radicals were involved in this transformation. Interestingly, changing vinylsilane (1a) to vinylether $(\mathbf{1} \mathbf{u})$ produced a seven-membered ring compound 12 (CCDC 2034125) instead of 
a
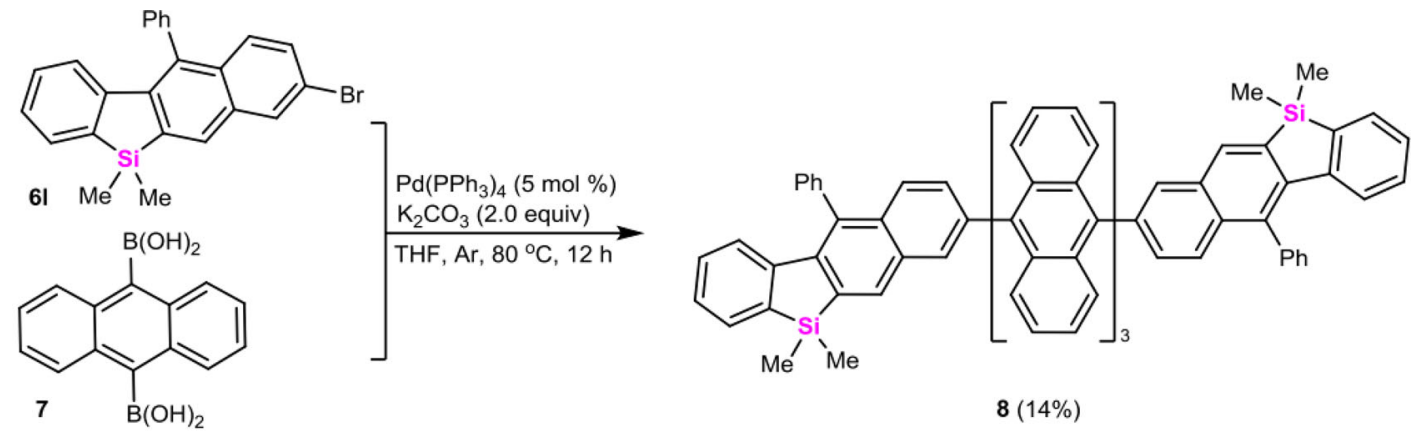

b

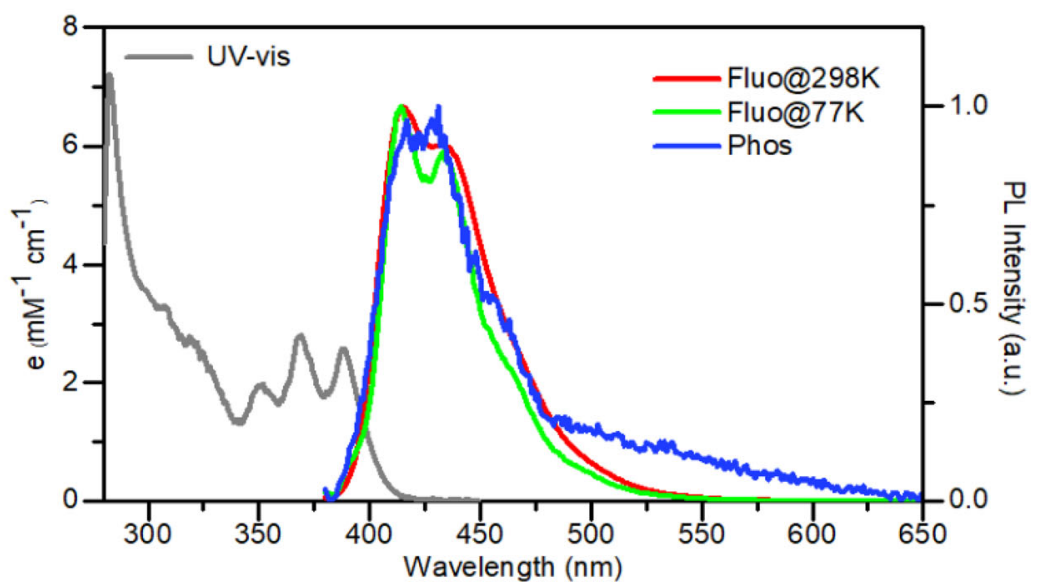

Fig. 6 Synthetic applications of this method. a Synthesis of $\pi$-conjugated teranthracene-tethered 1-phenyl-2,3-benzosilafluorene 8. b UV-vis absorption and PL spectra of benzosilafluorene 8 measured in diluted toluene solution $\left(10^{-5} \mathrm{M}\right)$ (a.u. refers to the arbitrary unit. Fluo@298K refers to the fluorescence spectra measured at $298 \mathrm{~K}$. Fluo@77K refers to the fluorescence spectra measured at $77 \mathrm{~K}$. Phos refers to the phosphorescence spectra.).

cycloaromatization product 13 (Fig. 7c). This experiment demonstrated that $\mathrm{Si} / \mathrm{O}$ switch significantly affected the reaction pathway of vinylsilanes, in which sulfonyl radicals derived from sulfonyl azides preferred to attack carbon-carbon double bonds instead of carbon-carbon triple bonds. Furthermore, compared to para- or meta-methylphenylsulfonyl azides (3a in Fig. 3, $\mathbf{6 b} / \mathbf{6 c}$ in Fig. 5), the coupling-cyclization of ortho-methylphenylsulfonyl azide 2 s with vinylsilane 1a only afforded a $16 \%$ yield of non-aromatized silacycle 14 (CCDC 2064550), and the aromatized silacycle $\mathbf{6 u}$ was not obtained possibly due to that steric hindrance of ortho-methyl substituent of $2 \mathrm{~s}$ inhibited a potential structural arrangement and subsequent aromatization (Fig. 7d).

Phosphorescence spectra of the diluted toluene solutions detected at $77 \mathrm{~K}$ with a delay time of $0.05 \mathrm{~ms}$ were employed to determine the triplet energies of PC1 $(2.58 \mathrm{eV})$ and $\mathrm{TsN}_{3}(3.10$ eV) (Supplementary Fig. 2), demonstrating that an energy transfer (EnT) process between the excited state ${ }^{*} \operatorname{Ir}(\mathrm{III})$-catalyst PC1 and $\mathrm{TsN}_{3}$ could not occur. Meanwhile, the reduction potential difference $(\sim 0.39 \mathrm{~V})$ between PC1 $\left(E_{\text {III/IV }}:-1.45 \mathrm{~V}\right.$ versus $\mathrm{Ag} / \mathrm{AgNO}_{3}$ in $\left.\mathrm{CH}_{3} \mathrm{CN}\right)$ and $\mathrm{TsN}_{3}\left(E_{\text {red }}:-1.06 \mathrm{~V}\right.$ vs $\mathrm{Ag} /$ $\mathrm{AgNO}_{3}$ in $\mathrm{CH}_{3} \mathrm{CN}$ ) (see Supplementary Information for the cyclic voltammetry (CV) of $\mathrm{TsN}_{3}$ and $\mathrm{Ir}(\mathrm{III})$-catalyst PC1) means that the electron transfer between them possibly occurred under heating conditions (Supplementary Figs. 4 and 5). Moreover, the fluorescence quenching (Supplementary Figs. 6 and 7) further suggested that a possible SET process between the excited state ${ }^{*} \mathrm{Ir}(\mathrm{III})$-catalyst and $\mathrm{TsN}_{3}$ led to the formation of sulfonyl radicals via nitrene radicals ${ }^{52}$ and arylsulfonyldiimide ${ }^{48}$. Calibrated with DFT calculations, the possible reaction mechanism is shown in Fig. 8. In Path a, the addition of sulfonyl radical to the carbon-carbon double bond in substrate $\mathbf{1 a}$ results in $\alpha$-silyl carbon radical $\mathbf{A}(5.6 \mathrm{kcal} / \mathrm{mol})$, which could further undergo the radical cyclization with carbon-carbon triple bond to afford vinylradical $\mathbf{B}(-11.6 \mathrm{kcal} / \mathrm{mol})$. Intramolecular cyclization of $\mathbf{B}$ at the benzene ring followed by the Smiles rearrangement involved a spirocyclic intermediate C $(-12.7$ $\mathrm{kcal} / \mathrm{mol}$ ) and a subsequent desulfonylation to produce beta-silyl radical D $(-29.9 \mathrm{kcal} / \mathrm{mol})$. Again, the cascade radical cyclization to $\mathbf{E}(-41.4 \mathrm{kcal} / \mathrm{mol}), \mathrm{SET}$, and aromatization give the cycloaromatization product $\mathbf{3 a}$. In contrast, Ts• radical could attack the carbon-carbon triple bond of $\mathbf{1 a}$ in Path $\mathrm{b}$, leading to ethylenic radical $\mathbf{G}(8.0 \mathrm{kcal} / \mathrm{mol})$, which then forms radical intermediate $\mathbf{H}(-2.0 \mathrm{kcal} / \mathrm{mol})$ and $\mathbf{I}(-4.8 \mathrm{kcal} / \mathrm{mol})$ through cascade cyclization. Although intermediate I could be converted to $\mathbf{E}$ by desulfonylation, control experiments and DFT calculations both suggest Path a to be the more plausible mechanism. Because of that ortho-methylphenylsulfonyl azide $2 \mathrm{~s}$ was subjected to the standard photocatalyzed system, although ortho-methylphenylsulfonyl radical could attack the carboncarbon double bond of 1a, the steric hindrance from orthomethyl substituent of $2 \mathrm{~s}$ possibly inhibited the formation of the spirocyclic intermediate $\mathbf{C}$ (Path a), resulting in very poor yield (16\%) of non-aromatized silacycle 14 (see Supplementary Information for the HMBC, NOE spectra and single crystal structure (Supplementary Figs. 8, 9, and 15) of compound 14) through cascade radical cyclization and desulfonylation. This control experiment (Fig. 7d) indirectly implied that the cycloaromatization between vinylsilanes and arylsulfonyl azides via Path b (Fig. 8) was not possible. 

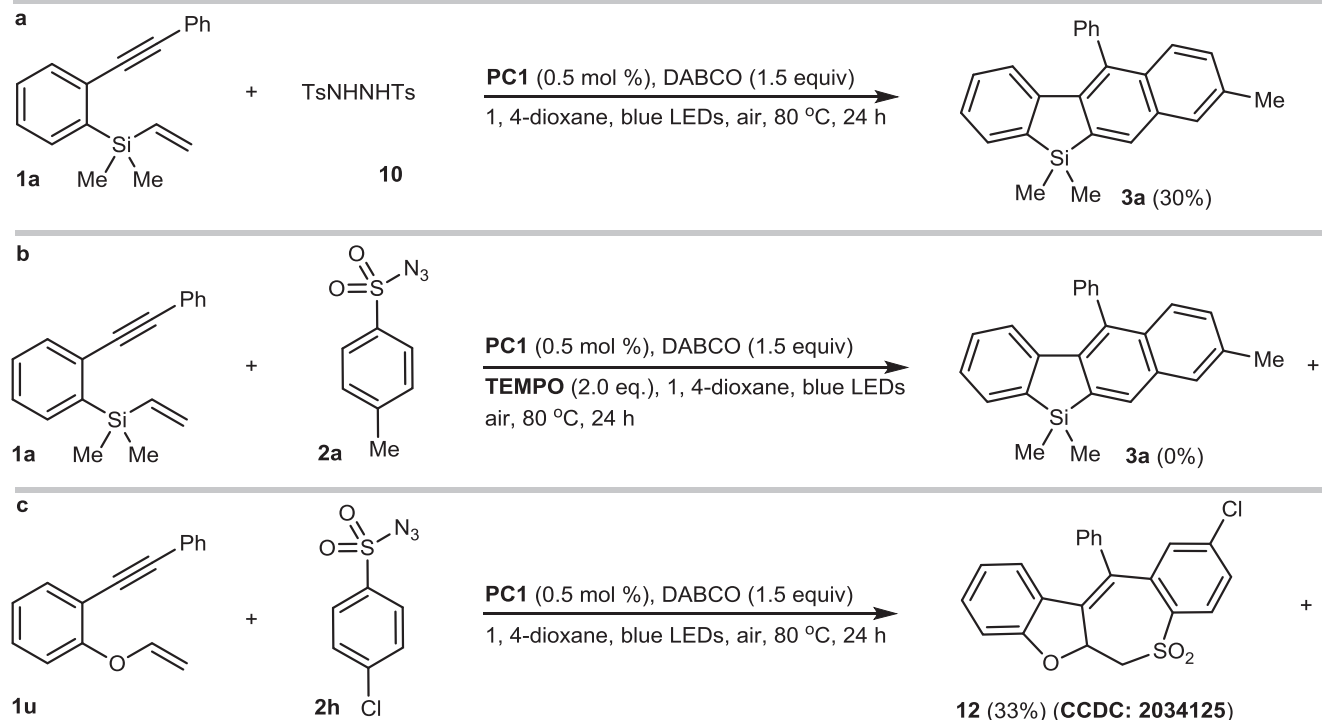

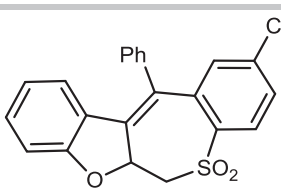

12 (33\%) (CCDC: 2034125$)$

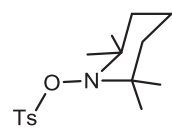

11 (detected by HR-MS)<smiles>C=C[Si](C)(C)c1ccccc1C#Cc1ccccc1</smiles>

$1 \mathrm{a}$ 2h Cl<smiles></smiles>

$6 \mathrm{u}(0 \%)$
1, 4-dioxane, blue LEDs, air, $80^{\circ} \mathrm{C}, 24 \mathrm{~h}$

Fig. 7 Preliminary mechanism studies. a Photocatalyzed cycloaromatization of vinylsilane 1a with sulfonylhydrazine 10. b Radical intermediate trapping reaction by TEMPO. c Photocatalyzed coupling-cyclization of vinylether $\mathbf{1} \mathbf{u}$ with arylsulfonylazide $\mathbf{2 h}$. $\mathbf{d}$ Photocatalyzed coupling-cyclization of vinylsilane $\mathbf{1 a}$ with ortho-methylphenylsulfonyl azide $\mathbf{2 s .}$

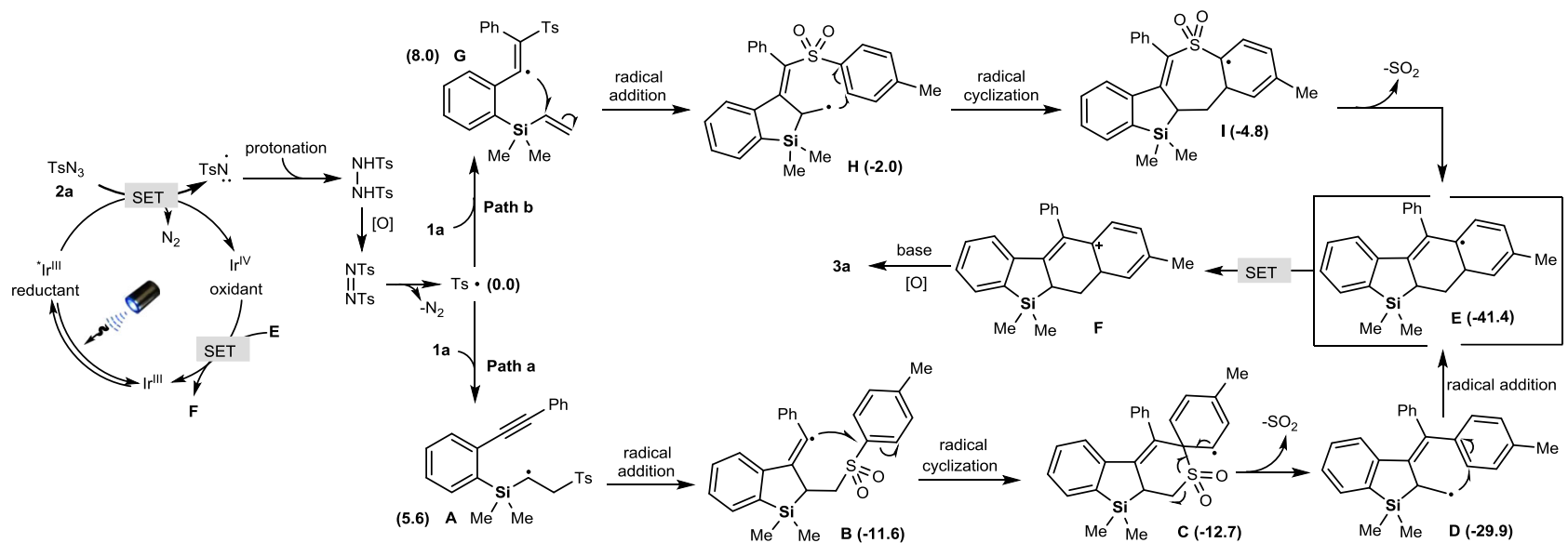

Fig. 8 Proposed reaction mechanism. Cycloaromatization of vinylsilanes with arylsulfonylazides via Path a and Path b.

\section{Discussion}

In conclusion, we have reported a photoredox-catalyzed cycloaromatization of ortho-alkynylaryl vinylsilanes and arylsulfonyl azides, furnishing naphthyl-fused benzosilole skeletons with wide functional group tolerance. This protocol features a unique combination of cascade S-N/C-S bond cleavages and $\alpha$-silyl radical Smiles rearrangement. These silaarenes show promising potential in luminescent materials, and further application studies of these highly $\pi$ conjugated siloles in luminescent materials are undergoing in our lab.

\section{Methods}

Procedure for the photocatalyzed cycloaromatization of vinylsilanes with arylsulfonylazides. To a $10 \mathrm{~mL}$ vial equipped with a magnetic stir bar, was added vinylsilanes $1(0.2 \mathrm{mmol})$, arylsulfonylazides $2(0.8 \mathrm{mmol})$, DABCO $(33 \mathrm{mg}, 0.3$ $\mathrm{mmol}),\left[\operatorname{Ir}\left\{\mathrm{dt}(\mathrm{tBu})_{2} \mathrm{ppy}\right\}_{2}(\mathrm{dtbbpy})\right]\left[\mathrm{PF}_{6}\right] \mathbf{P C 1}(1.3 \mathrm{mg}, 0.5 \mathrm{~mol} \%)$ and 1,4-dioxane $(2.0 \mathrm{~mL})$ under air conditions. The vial was equipped with a Teflon septum and stirred at $80^{\circ} \mathrm{C}$ under blue LED irradiation with two Kessil LEDs ( $30 \mathrm{~W}, 456 \mathrm{~nm}$, $\sim 3 \mathrm{~cm}$ away from the reaction mixture) for $24 \mathrm{~h}$. The solvent was removed in vacuo and the residue was purified by flash column chromatography on silica gel to yield the desired products.

\section{Data availability}

The authors declare that the data supporting the findings of this study are available within the article as well as from the authors upon reasonable request. The X-ray crystallographic coordinates for structures $3 a, 5 c, 12$, and 14 reported in this study have been deposited at the Cambridge Crystallographic Data Centre (CCDC) under CCDC 2034071, CCDC 2034073, CCDC 2034125, and CCDC 2064550, respectively. These data can be obtained free of charge from The Cambridge 
Crystallographic Data Centre via www.ccdc.cam.ac.uk/data-request/cif. Source data are provided with this paper.

Received: 30 November 2020; Accepted: 26 April 2021; Published online: 03 June 2021

\section{References}

1. Tacke, R. \& Metz, S. Odorant design based on the carbon/silicon switch strategy. Chem. Biodivers. 5, 920-941 (2008).

2. Friedrich, J., Dorrich, S., Berkefeld, A., Kraft, P. \& Tacke, R. Synthesis and olfactory characterization of sila-methyl pamplemousse and related odorants with a 2,2,5-trimethyl-2-silahex-4-ene skeleton. Organometallics 33, 796-803 (2014).

3. Driess, M. \& Oestreich, M. New frontiers and challenges in silicon chemistry: ISOS XVII in berlin. Chem. Eur. J. 20, 9144-9145 (2014).

4. Shimizu, M. \& Hiyama, T. Silicon-bridged biaryls: molecular design, new synthesis, and luminescence control. Synlett 23, 973-989 (2012).

5. Förster, B., Bertermann, R., Kraft, P. \& Tacke, R. Sila-rhubafuran and derivatives: synthesis and olfactory characterization of novel siliconcontaining odorants. Organometallics 33, 338-346 (2014).

6. Pujals, S. et al. Replacement of a proline with silaproline causes a 20-fold increase in the cellular uptake of a pro-rich peptide. J. Am. Chem. Soc. 128 8479-8483 (2006).

7. Lukevics, E., Germane, S., Segal, I. \& Zablotskaya, A. Silyl modification of biologically active compounds. Chem. Heterocycl. Compd. 33, 234-238 (1997).

8. Lippert, W.-P. et al. Silicon analogues of the RXR-selective retinoid agonist SR11237 (BMS649): chemistry and biology. ChemMedChem 4, 1143-1152 (2009).

9. Kumagai, T. \& Itsuno, S. Asymmetric allylation polymerization of bis (allylsilane) and dialdehyde containing arylsilane structure. Macromolecules 35, 5323-5325 (2002).

10. Bai, D., Han, S., Lu, Z.-H. \& Wang, S. Bright blue luminescent pyrenyl-containing organosilicon compounds with contrasting charge transport functionality$\mathrm{SiPh}_{2}\left(p-\mathrm{C}_{6} \mathrm{H}_{4}\right.$-pyrenyl $)\left(p-\mathrm{C}_{6} \mathrm{H}_{4}-\mathrm{N}\right.$-benzimidazolyl $)$ and $\mathrm{SiPh}_{2}\left(p-\mathrm{C}_{6} \mathrm{H} 4\right.$-pyrenyl $)$ [ $\left.p-\mathrm{C}_{6} \mathrm{H}_{4}-\mathrm{NPh}(1-n a p h)\right]$. Can. J. Chem. 86, 230-237 (2008).

11. Shirota, Y. \& Kageyama, H. Charge carrier transporting molecular materials and their applications in devices. Chem. Rev. 107, 953-1010 (2007).

12. Cui, Y.-M., Lin, Y. \& Xu, L.-W. Catalytic synthesis of chiral organoheteroatom compounds of silicon, phosphorus, and sulfur via asymmetric transition metal-catalyzed C-H functionalization. Coord. Chem. Rev. 330, 37-52 (2017).

13. Ilies, L., Sato, Y., Mitsui, C., Tsuji, H. \& Nakamura, E. Modular synthesis of polybenzo[b]silole compounds for hole-blocking material in phosphorescent organic light emitting diodes. Chem. Asian J. 5, 1376-1381 (2010).

14. Liang, Y., Geng, W.-Z., Wei, J.-N. \& Xi, Z.-F. Palladium-catalyzed intermolecular coupling of 2-silylaryl bromides with alkynes: synthesis of benzosiloles and heteroarene-fused siloles by catalytic cleavage of the $\mathrm{C}$ $\left(\mathrm{sp}^{3}\right)-$ Si bond. Angew. Chem. Int. Ed. 51, 1934-1937 (2012).

15. Onoe, M. et al. Rhodium-catalyzed carbon-silicon bond activation for synthesis of benzosilole derivatives. J. Am. Chem. Soc. 134, 19477-19488 (2012).

16. Zhang, Q.-W., An, K. \& He, W. Rhodium-catalyzed tandem cyclization/Si-C activation reaction for the synthesis of siloles. Angew. Chem. Int. Ed. 53, 5667-5671 (2014).

17. Minami, Y., Noguchi, Y. \& Hiyama, T. Synthesis of benzosiloles by intramolecular anti-hydroarylation via ortho-C-H activation of aryloxyethynyl silanes. J. Am. Chem. Soc. 139, 14013-14016 (2017).

18. Shintani, R., Takano, R. \& Nozaki, K. Rhodium-catalyzed asymmetric synthesis of silicon-stereogenic silicon-bridged arylpyridinones. Chem. Sci. 7, 1205-1211 (2016).

19. Mocanu, A. et al. Synthesis, optical, and redox properties of regioisomeric benzoheterocycles-fused pyrene. J. Org. Chem. 84, 957-962 (2019).

20. Leifert, D. \& Studer, A. 9-Silafluorenes via base-promoted homolytic aromatic substitution (BHAS) - the electron as a catalyst. Org. Lett. 17, 386-389 (2015).

21. Yang, C. et al. Visible-light induced radical silylation for the synthesis of dibenzosiloles via dehydrogenative cyclization. Adv. Synth. Catal. 360, 3049-3054 (2018).

22. Zhang, Q. W. et al. Rhodium-catalyzed intramolecular $\mathrm{C}-\mathrm{H}$ silylation by silacyclobutanes. Angew. Chem. Int. Ed. 55, 6319-6323 (2016).

23. Snape, T.-J. A truce on the smiles rearrangement: revisiting an old reactionthe truce-smiles rearrangement. Chem. Soc. Rev. 37, 2452-2458 (2008).

24. Holden, C.-M. \& Greaney, M.-F. Modern aspects of the smiles rearrangement. Chem. Eur. J. 23, 8992-9008 (2017).

25. Ramazani, A., Moradnia, F., Aghahosseini, H. \& Abdolmaleki, I. Several species of nucleophiles in the smiles rearrangement. Curr. Org. Chem. 21, 1612-1625 (2017).
26. Fuentes, N., Kong, W.-Q., Fernández - Sánchez, L., Merino, E. \& Nevado, C. Cyclization cascades via $\mathrm{N}$-amidyl radicals toward highly functionalized heterocyclic scaffolds. J. Am. Chem. Soc. 137, 964-973 (2015).

27. Zhang, $\mathrm{H}$. et al. Metal-free cascade construction of $\mathrm{C}-\mathrm{C}$ bonds by activation of inert $\mathrm{C}\left(\mathrm{sp}^{3}\right)-\mathrm{H}$ bonds. Chem. Commun. 51, 1320-1322 (2015).

28. Huang, H. \& Li, Y.-J. Sustainable difluoroalkylation cyclization cascades of 1,8-enynes. J. Org. Chem. 82, 4449-4457 (2017).

29. Kong, W., Fuentes, N., García-Domínguez, A., Merino, E. \& Nevado, C. Stereoselective synthesis of highly functionalized indanes and dibenzocycloheptadienes through complex radical cascade reactions. Angew. Chem. Int. Ed. 54, 2487-2491 (2015).

30. Tan, F.-L., Song, R.-J., Hu, M. \& Li, J.-H. Metal-free oxidative 1,2arylmethylation cascades of $\mathrm{N}$-(arylsulfonyl)acrylamides using peroxides as the methyl resource. Org. Lett. 18, 3198-3201 (2016).

31. Monos, T.-M., McAtee, R.-C. \& Stephenson, C. R. J. Ary-sulfonylacetamides as bifunctional reagents for alkene aminoarylation. Science 361, 1369-1373 (2018).

32. Alpers, D., Cole, K.-P. \& Stephenson, C. R. J. Visible light mediated aryl migration by homolytic $\mathrm{C}-\mathrm{N}$ cleavage of aryl amines. Angew. Chem. Int. Ed. 57, 12167-12170 (2018).

33. Whalley, D.-M., Duong, H.-A. \& Greaney, M.-F. Alkene carboarylation through catalyst-free, visible light-mediated smiles rearrangement. Chem. Eur. J. 25, 1927-1930 (2019).

34. Brachet, E., Marzo, L., Selkti, M., König, B. \& Belmont, P. Visible light amination/Smiles cascade:access to phthalazine derivatives. Chem. Sci. 7, 5002-5006 (2016)

35. Wang, Z.-S. et al. Ynamide smiles rearrangement triggered by visible-lightmediated regioselective ketyl-ynamide coupling: rapid access to functionalized indoles and isoquinolines. J. Am. Chem. Soc. 142, 3636-3644 (2020).

36. Denmark, S.-E. \& Sweis, R.-F. Design and implementation of new, siliconbased, cross-coupling reactions: Importance of silicon-oxygen bonds. Acc. Chem. Res. 35, 835-846 (2002).

37. Simons, G., Zandler, M.-E. \& Talaty, E.-R. Nonempirical electronegativity scale. J. Am. Chem. Soc. 98, 7869-7870 (1976).

38. Hanstein, W., Berwin, H.-J. \& Traylor, T.-G. Modes of carbonium ion stabilization. Evidence from charge-transfer spectra. J. Am. Chem. Soc. 92, 829-836 (1970).

39. Wierschke, S.-G., Chandrasekha, J. \& Jorgensen, W.-L. Magnitude and origin of the beta-silicon effect on carbenium ions. J. Am. Chem. Soc. 107, 1496-1500 (1985).

40. Blumenkopf, T.-A. \& Overman, L.-E. Vinylsilan- and alkynylsilaneterminated cyclization reactions. Chem. Rev. 86, 857-873 (1986).

41. Park, J.-W. \& Jun, C.-H. Transition metal-catalyzed immobilization of organic functional groups onto solid supports through vinylsilane coupling reactions. J. Am. Chem. Soc. 132, 7268-7269 (2010).

42. Niljianskul, N., Zhu, S.-L. \& Buchwald, S.-L. Enantioselective synthesis of $\alpha$ aminosilanes by copper-catalyzed hydroamination of vinylsilanes. Angew. Chem. Int. Ed. 54, 1638-1641 (2015).

43. Kato, K., Hirano, K. \& Miura, M. Synthesis of $\beta$-boryl- $\alpha$-aminosilanes by copper-catalyzed aminoboration of vinylsilanes. Angew. Chem. Int. Ed. 55, 14400-14404 (2016).

44. Huang, X., Webster, R. D., Harms, K. \& Meggers, E. Asymmetric catalysis with organic azides and diazo compounds initiated by photoinduced electron transfer. J. Am. Chem. Soc. 138, 12636-12642 (2016).

45. Park, H. et al. Highly rigid and twisted anthracene derivatives: a strategy for deep blue OLED materials with theoretical limit efficiency. J. Mater. Chem. 22, 2695-2700 (2012)

46. Brachet, E., Ghosh, T., Ghosh, I. \& Konig, B. Visible light C-H amidation of heteroarenes with benzoyl azides. Chem. Sci. 6, 987-992 (2015).

47. Zhu, S. et al. Sulfonylative and azidosulfonylative cyclizations by visible-lightphotosensitization of sulfonyl azides in THF. Chem. Eur. J. 23, 17598-17604 (2017).

48. Maioli, A.-T. \& Anselme, J.-P. Oxidation of 1,2-bis-(benzenesulfonyl) hydrazine to 1,2- diphenyldisulfone. Tetrahedron Lett. 36, 1221-1222 (1995).

49. Yilmaz, O., Oderinde, M. S. \& Emmert, M. H. Photoredox-catalyzed Ca-H cyanation of unactivated secondary and tertiary aliphatic amines: late-stage functionalization and mechanistic studies. J. Org. Chem. 83, 11089-11100 (2018).

50. Luo, D. et al. N,N-disulfonylhydrazines: new sulfonylating reagents for highly efficient synthesis of $(E)$-vinyl sulfones at room temperature. Tetrahedron 76, 131019 (2020).

51. Liang, T. et al. Transition metal-free C5 tosyloxylation of 8-aminoquinolines with phenyliodine bistrifluoroacetate and substituted 1,2-disulfonyl hydrazides. Eur. J. Org. Chem. 2019, 2513-2519 (2019).

52. Singha, K., Mondal, A., Ghosh, S. C. \& Panda, A. B. Visible-light-driven efficient photocatalytic reduction of organic azides to amines over CdS sheetrGO nanocomposite. Chem. Asian J. 13, 255-260 (2018). 


\section{Acknowledgements}

We thank NKRDPC (No. 2016YFA0602900), the NSFC (Nos. 21871097, 51625301, 21973113), KARDPGP (No. 2020B010188001), NSFGP (Nos. 2018B030308007,

2019A1515011790), and STPG (No. 201904010113) for financial support.

\section{Author contributions}

W.Z. conceived and directed the project. F.C. performed the experiments. M.L. and C.Y. prepared some substrates. H.J. joined the discussion about this project. Y.S. performed the DFT calculations. Z.K. directed the DFT calculations. S.-J.S. directed the photophysical experiments. W.Z. wrote the manuscript.

\section{Competing interests}

The authors declare no competing interests.

\section{Additional information}

Supplementary information The online version contains supplementary material available at https://doi.org/10.1038/s41467-021-23326-2.

Correspondence and requests for materials should be addressed to S.-J.S., Z.K. or W.Z.
Peer review information Nature Communications thanks the anonymous reviewers for their contribution to the peer review of this work. Peer reviewer reports are available.

Reprints and permission information is available at http://www.nature.com/reprints.

Publisher's note Springer Nature remains neutral with regard to jurisdictional claims in published maps and institutional affiliations.

\section{(c) (i)}

Open Access This article is licensed under a Creative Commons Attribution 4.0 International License, which permits use, sharing, adaptation, distribution and reproduction in any medium or format, as long as you give appropriate credit to the original author(s) and the source, provide a link to the Creative Commons license, and indicate if changes were made. The images or other third party material in this article are included in the article's Creative Commons license, unless indicated otherwise in a credit line to the material. If material is not included in the article's Creative Commons license and your intended use is not permitted by statutory regulation or exceeds the permitted use, you will need to obtain permission directly from the copyright holder. To view a copy of this license, visit http://creativecommons.org/licenses/by/4.0/.

(c) The Author(s) 2021 